\title{
Saturnispora quitensis sp. nov., a yeast species isolated from the Maquipucuna cloud forest reserve in Ecuador
}

Correspondence

Stephen A. James steve.james@bbsrc.ac.uk

\author{
Stephen A. James, ${ }^{1}$ Geneviève M. Cadet $^{2}{ }^{2}$ \\ Enrique Javier Carvajal Barriga, ${ }^{3}$ Patricia Portero Barahona, ${ }^{3}$ \\ Kathryn Cross, ${ }^{4}$ Christopher J. Bond ${ }^{1}$ and lan N. Roberts ${ }^{1}$ \\ ${ }^{1}$ National Collection of Yeast Cultures (NCYC), Institute of Food Research, Norwich Research Park,
Colney, Norwich, UK \\ ${ }^{2}$ Institut Universitaire de Technologie (IUT) de Saint-Pierre, Département Génie Biologique, \\ Saint-Pierre, lle de la Réunion \\ ${ }^{3}$ Colección de Levaduras Quito Católica (CLQCA), Centro Neotropical para Investigación de la \\ Biomasa, Pontificia Universidad Católica del Ecuador, Escuela de Ciencias Biológicas, Quito, \\ Ecuador \\ ${ }^{4}$ Imaging and Microscopy Group (IMG), Institute of Food Research, Norwich Research Park, Colney, \\ Norwich, UK
}

\begin{abstract}
A single strain, CLQCA-10-114 ${ }^{\top}$, representing a novel yeast species belonging to the genus Saturnispora was isolated from the fruit of an unidentified species of bramble (Rubus sp.), collected from the Maquipucuna cloud forest reserve, near Quito, in Ecuador. Sequence analyses of the D1/D2 domains of the large-subunit rRNA gene and ribosomal internal transcribed spacer region indicated that the novel species is most closely related to the recently described species Saturnispora gosingensis, isolated from the fruiting body of a mushroom collected in Taiwan, and Saturnispora hagleri, a Drosophila-associated yeast found in Brazil. The name Saturnispora quitensis sp. nov. is proposed to accommodate this strain; the type strain is CLQCA-10-114 ${ }^{\top}$ $\left(=\right.$ CBS $12184^{\top}=$ NCYC $\left.3744^{\top}\right)$.
\end{abstract}

The yeast genus Saturnispora is characterized by teleomorphic species that typically produce one to four spheroidal ascospores ornamented with an equatorial ledge (i.e. saturnshaped) and have a fairly restricted physiological profile (Kurtzman, 1998). The genus is well-supported by phylogenetic analyses based on multigene sequence analysis of the small-subunit and large-subunit (LSU) rRNA genes, and translation elongation factor- $1 \alpha$ gene (Kurtzman et al., 2008). At present, the genus comprises nine teleomorphic species: Saturnispora ahearnii, Saturnispora besseyi, Saturnispora dispora, Saturnispora gosingensis, Saturnispora hagleri, Saturnispora mendoncae, Saturnispora saitoi, Saturnispora serradocipensis and Saturnispora zaruensis (Morais et al., 2005; Kurtzman, 2006; Kurtzman et al., 2008; Canelhas et al.,

tPresent address: Department of Biological Sciences, University of Bordeaux, Bordeaux, France.

Abbreviations: ITS, internal transcribed spacer; LSU, large-subunit.

The GenBank/EMBL/DDBJ accession numbers for the LSU D1/D2 and ITS sequences of CLOCA-10-114 ${ }^{\top}$ are FN908197 and FN985101, respectively.

A supplementary figure is available with the online version of this paper.
2011). Six anamorphic species, Candida diversa, Candida sanitii, Candida sekii, Candida siamensis, Candida silvae and Candida suwanaritii, are also accommodated within the genus (Kurtzman et al., 2008; Boonmak et al., 2009; Limtong et al., 2010). Collectively, these yeasts have been isolated from a wide variety of different sources and habitats including Drosophila flies (Drosophila cardinae and Drosophila fascioloides), estuarine water from mangrove forest, flowers, forest soil, insect frass, leaf detritus, marsh water, rhizosphere of oyster grass, sauerkraut, tree bark and exudate (Quercus spp.), and wild mushrooms (Coprinus and Hygrophorus spp.) (Liu \& Kurtzman, 1991; Kurtzman, 1998; Morais et al., 2005; Boonmak et al., 2009; Canelhas et al., 2011; Limtong et al., 2010).

During a pilot study to survey yeast diversity found in the Maquipucuna cloud forest nature reserve, located 50 miles north-west of Quito, Ecuador ( $0^{\circ} 03^{\prime} 09^{\prime \prime} \mathrm{N} 78^{\circ} 41^{\prime} 06^{\prime \prime} \mathrm{W}$; $1668 \mathrm{~m}$ above sea-level), CLQCA-10-114 ${ }^{\mathrm{T}}$ was isolated together with more than 70 other yeast strains. Sequence analysis of the D1/D2 domain of the LSU rRNA gene identified the isolates as belonging to 25 different species of the genera Barnettozyma (1 isolate), Candida (6), Hanseniaspora 
(2), Lachancea (1), Lodderomyces (1), Metschnikowia (2), Pichia (3), Rhodotorula (1), Saccharomyces (1), Saturnispora (1), Trichosporon (2), Wickerhamomyces (3) and Yarrowia (1). Strain CLQCA-10-114 ${ }^{\mathrm{T}}$ was isolated from the fruit of an unidentified species of bramble (Rubus sp.) and, based on its physiology and ability to produce saturn-shaped ascospores, was identified as a representative of the genus Saturnispora (Kurtzman, 1998). Subsequent sequence analyses of the LSU D1/D2 domain and ribosomal internal transcribed spacer (ITS) region established that this strain belongs to a genetically distinct and hitherto undescribed species closely related to $S$. hagleri and the recently described S. gosingensis (isolated in Taiwan) and S. serradocipensis (isolated in south-eastern Brazil) (Canelhas et al., 2011). The name Saturnispora quitensis sp. nov. is proposed in recognition of the location in Ecuador where it was first found.

The variable D1/D2 domain of the LSU rRNA gene and ribosomal ITS region were amplified by PCR directly from whole yeast cell suspensions as described previously by James et al. (1996). The LSU D1/D2 domain was amplified and sequenced using primers NL1 and NL4 (O'Donnell, 1993). The ITS region was amplified using primers ITS5 and ITS4, and sequenced using these primers as well as internal primers ITS2 and ITS3 (White et al., 1990). PCR products were checked by agarose gel electrophoresis, purified and concentrated using QIAquick PCR purification columns
(Qiagen), and sequenced using a Life Technologies 3730XL sequencer at The Genome Analysis Centre, Norwich, UK. Sequence traces were edited and consensus sequences were generated using the program SEQMAN version 7 (DNASTAR). The LSU D1/D2 sequences were compared pairwise using a FASTA similarity search (Pearson \& Lipman, 1988) and were aligned with sequences of closely related taxa using the multiple alignment program CLUSTAL W (Thompson et al., 1994), included in the software package DNAMAN version 5.1.5 (Lynnon BioSoft). A phylogenetic tree was constructed using the neighbour-joining method (Saitou \& Nei, 1987) with the Jukes-Cantor distance measure. Confidence limit values were estimated from bootstrap analyses of 1000 replicates (Felsenstein, 1985).

Phylogenetic analysis based on LSU D1/D2 sequences showed that CLQCA-10-114 ${ }^{\mathrm{T}}$ was placed on a separate branch within the Saturnispora clade (Fig. 1). In terms of pairwise sequence similarity, CLQCA-10-114 $4^{\mathrm{T}}$ displayed $0.8 \%$ divergence (4 nt substitutions) with S. gosingensis, $1.1 \%$ divergence (3 nt substitutions and two indels) with $S$. hagleri and $1.3 \%$ divergence (5 nt substitutions and one indel) with $S$. serradocipensis. Indeed, along with $S$. dispora (2.6\% divergence; $12 \mathrm{nt}$ substitutions and two indels), $S$. zaruensis (3.9\% divergence; $18 \mathrm{nt}$ substitutions), Candida agrestis ES3M03 (3.3\% divergence; $16 \mathrm{nt}$ substitutions and one indel) and Saturnispora sp. GJ5M11 (3.3\% divergence;

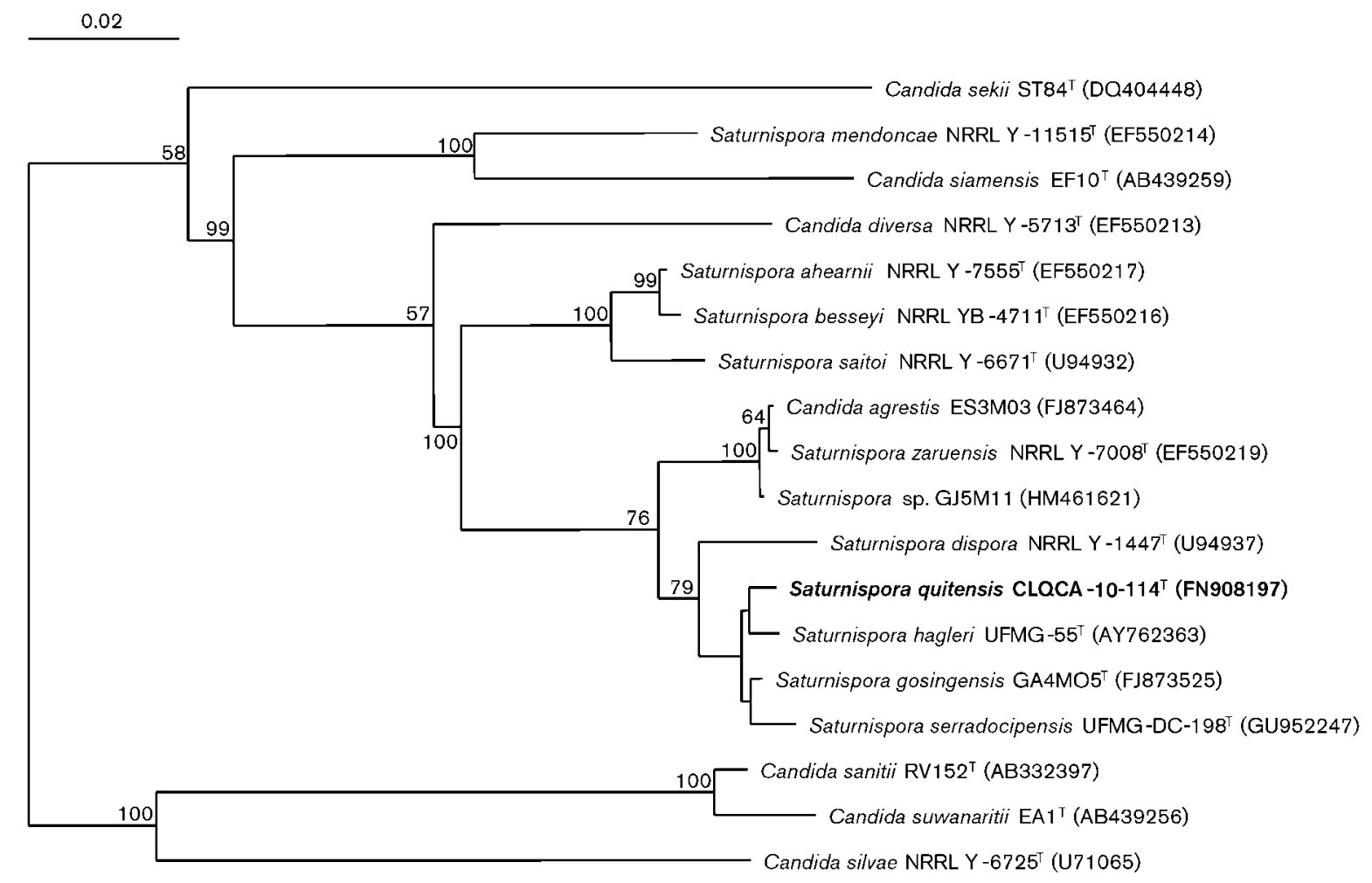

Fig. 1. Neighbour-joining dendrogram based on sequences of the D1/D2 domain of the LSU rRNA gene of Saturnispora quitensis sp. nov. and its closest relatives. Bootstrap values $\geqslant 50 \%$, determined from 1000 replicates, are shown at branch nodes. Bar, 2 base substitutions per $100 \mathrm{nt}$. 
$17 \mathrm{nt}$ substitutions), these taxa form a distinct and separate species subgroup within the Saturnispora clade (Fig. 1). Despite the close phylogenetic relationship based on LSU D1/D2 sequences (0.8-1.3\% sequence divergence), strain CLQCA-10-114 ${ }^{\mathrm{T}}$, S. gosingensis GA4M05 ${ }^{\mathrm{T}}\left(=\mathrm{MRC}^{-2010 \mathrm{a}^{\mathrm{T}}}\right)$, S. hagleri UFMG- $55^{\mathrm{T}}$ and S. serradocipensis UFMG-DC- $198^{\mathrm{T}}$ $\left(=\mathrm{MRC}-2010 \mathrm{~b}^{\mathrm{T}}\right)$ can be readily distinguished from one another by ITS sequencing.

Although only partial ITS1 sequences currently exist for $S$. gosingensis GA4M $05^{\mathrm{T}}$, S. hagleri UFMG- $55^{\mathrm{T}}$ and S. serradocipensis UFMG-DC-198 ${ }^{\mathrm{T}}$, all three strains still differ from CLQCA- $10-114^{\mathrm{T}}$ by $6 \mathrm{nt}$ substitutions and two indels, $3 \mathrm{nt}$ substitutions and two indels, and by $1 \mathrm{nt}$ substitution and one indel, respectively. In the ITS2 region, for which there are complete sequences available, the variation is far more pronounced: S. gosingensis GA4M05 ${ }^{\mathrm{T}}$ differs by $17 \mathrm{nt}$ substitutions and one indel; S. hagleri UFMG- $55^{\mathrm{T}}$ by $28 \mathrm{nt}$ substitutions and four indels; and S. serradocipensis UFMGDC- $198^{\mathrm{T}}$ by 35 nt substitutions and five indels. In fact, the overall size of the ITS2 region varies quite markedly between the four Saturnispora strains ranging from 110 bp (UFMG$55^{\mathrm{T}}$ ) to $133 \mathrm{bp}$ (CLQCA-10-114 $4^{\mathrm{T}}$. Separate pairwise ITS alignments between S. quitensis CLQCA-10-114 ${ }^{\mathrm{T}}$ and the other three strains are shown in Supplementary Fig. S1 (available in IJSEM Online).

A similar situation exists between the closely related species pair of S. ahearnii and S. besseyi (formerly Pichia besseyi) (Fig. 1). On the basis of LSU D1/D2 sequence divergence, the two taxa appear to be conspecific, as they differ from one another by only two (single nucleotide) indels. However, when Kurtzman (2006) compared the ITS sequences of the type strains (S. ahearnii NRRL Y $-7555^{\mathrm{T}}$ and S. besseyi NRRL $\mathrm{YB}-4711^{\mathrm{T}}$ ), currently the only known representatives of these species, far greater sequence diversity was detected. In the ITS1 region, the two strains differ by four substitutions and eight indels, and in the ITS2 region, by five substitutions and seven indels (Kurtzman, 2006). When compared against the level of ITS sequence variation observed between three different strains of S. saitoi, Kurtzman (2006) reported that $S$. ahearnii and S. besseyi ( $P$. besseyi) had three times as many ITS substitutions relative to the number found among the three S. saitoi strains. Based on these results, he concluded that $S$. ahearnii and S. besseyi represent closely related species rather than divergent members of the same species (Kurtzman, 2006).

At present, it is difficult to generalize on the ecological niches of these four closely related species, as only a small number of strains currently exist ( $S$. gosingensis, 1 isolate; $S$. hagleri, 6, S. quitensis, 1; S. serradocipensis, 2) (Morais et al., 2005; Canelhas et al., 2011; data from this study). However, based on those isolates that have been identified, S. quitensis appears to be most similar to S. hagleri and S. serradocipensis as all three species have been found in the neotropics. $S$. hagleri has been isolated from two different species of Drosophila (D. cardinae and D. fascioloides) collected in an Atlantic rainforest site in Brazil (Morais et al., 2005), S. quitensis from a bramble fruit collected in a cloud forest site in Ecuador, and S. serradocipensis from leaf detritus in a tropical stream in south-eastern Brazil (Canelhas et al., 2011). In contrast, the solitary strain of S. gosingensis so far identified was isolated from the fruiting body of a mushroom (Coprinus sp.) collected in Taiwan (Canelhas et al., 2011). In their species description of S. hagleri, Morais et al. (2005) noted that of the six identified strains, four were recovered from the crops of $D$. cardinae. This led the authors to suggest that this yeast may colonize tropical fruits and substrates regularly visited by these flies and utilized as a food source. Although only a single strain of $S$. quitensis has so far been isolated, it seems plausible to speculate that, like S. hagleri, additional strains of $S$. quitensis could, in future, be isolated from Drosophila flies and other insects that visit and feed upon tropical fruits found in Maquipucuna and other neotropical regions.

Physiologically, Saturnispora yeasts are almost indistinguishable from one another (Kurtzman, 1998, 2006). As reported previously, species separation is restricted to a small number of growth characteristics, specifically the assimilation of glycerol, ribitol and trehalose, as well as the ability to form a pellicle on the surface of liquid media (Morais et al., 2005). S. quitensis, like S. gosingensis, S. hagleri and S. serradocipensis, assimilates both ribitol and trehalose, and is unable to form a pellicle (Morais et al., 2005; Canelhas et al., 2011). The only growth characteristic that appears to be discriminatory is the assimilation of glycerol. S. hagleri and S. serradocipensis both assimilate this carbon source, but this is a variable characteristic for S. gosingensis (Morais et al., 2005; Canelhas et al., 2011). In the case of $S$. quitensis, no growth was observed, even after prolonged incubation ( $4+$ weeks). Thus, in view of the fact that these four species are physiologically almost indistinguishable from one another, we strongly recommend that LSU D1/D2 and, in particular, ITS sequencing are used to reliably determine species identity.

\section{Latin diagnosis of Saturnispora quitensis James, Cadet, Bond, Carvajal et Roberts sp. nov.}

In medio liquido post dies duos cellulae globosae aut ovoidae (4-7 $\times 5-8 \mu \mathrm{m})$, cellulae singulae et aggregatae, per gemmationem multipolarem reproducentes. Post unum mensem sedimentum formatur. Pseudomycelium nec mycelium non formatur. Post dies octo in agaro glucose et extracti levidinis asci formatur. Asci stabiles. Glucosum fermentatur at non galactosum, maltosum, lactosum, raffinosum nec sucrosum. Glucosum, trehalosum, ethanolum, ribitolum, mannitolum, glucitolum, acidum lacticum et acidum succinicum assimilantur at non galactosum, L-sorbosum, sucrosum, maltosum, cellobiosum, lactosum, melibiosum, raffinosum, melezitosum, inulinum, amylum solubile, D-xylosum, L-arabinosum, D-arabinosum, Dribosum, L-rhamnosum, D-glucosaminum, methanolum, glycerolum, erythritolum, methyl $\alpha$-D-glucosidum, salicinum, acidum citricum nec inositolum. Ethylaminum et cadaverinum assimilantur at non kalium nitricum. Crescit in $30{ }^{\circ} \mathrm{C}$, at non crescit in $37{ }^{\circ} \mathrm{C}$. Non crescit in $10 \% \mathrm{NaCl} / 5 \%$ glucosum nec $50 \%$ 
glucosum. Materia amyloidea non formantur. Non crescit in $0.01 \%$ cycloheximido. Typus stirps CLQCA-10-114 ${ }^{\mathrm{T}}$ (=CBS $12184^{\mathrm{T}}=$ NCYC $\left.3744^{\mathrm{T}}\right)$.

\section{Description of Saturnispora quitensis sp. nov.}

Saturnispora quitensis (qui.ten'sis. N.L. fem. adj. quitensis of or belonging to Quito, the capital of Ecuador, near where this strain was isolated).

Cells are spheroidal to ovoid $(4-7 \times 5-8 \mu \mathrm{m})$ and occur singly or in groups after growth in YM broth for 2 days at $25{ }^{\circ} \mathrm{C}$. Budding is multilateral. Sediment is formed after 1 month, but no pellicle is observed. Pseudomycelia or true mycelia are not formed. After 8 days on agar media with a low nitrogen/carbon ratio (i.e. yeast carbon base with $0.01 \%$ ammonium sulphate), conjugated cells give rise to asci containing one to two spheroidal ascospores ornamented with an equatorial ledge (i.e. saturn-shaped) (Fig. $2 \mathrm{a}$ and $\mathrm{b})$. Ascospores are not liberated. Conjugation takes place between individual cells and, more commonly, between cells and their buds (Fig. 2a).
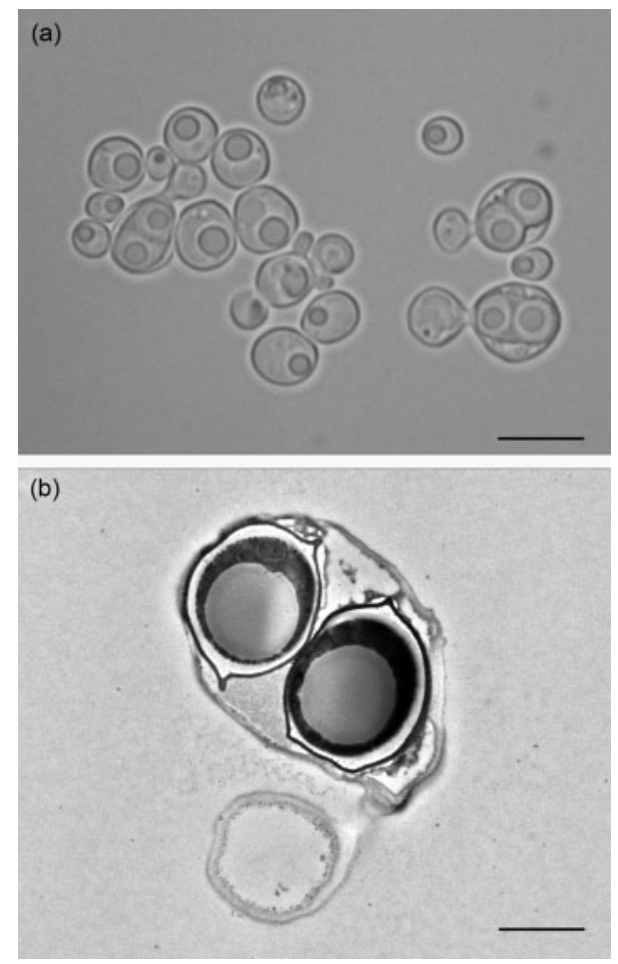

Fig. 2. Saturnispora quitensis sp. nov. CLQCA-10-114 ${ }^{\top}$. (a) Photomicrograph of cells grown on yeast carbon base supplemented with $0.01 \%$ ammonium sulphate after 8 days incubation at $20^{\circ} \mathrm{C}$. Note the vegetative cells, conjugation between three separate cells with their respective buds, and asci with two ascospores. Bar, $5 \mu \mathrm{m}$. (b) Transmission electron micrograph of a single ascus containing two ascospores, one of which is ornamented with an equatorial ledge. Bar, $1 \mu \mathrm{m}$.
Glucose is fermented. Galactose, maltose, lactose, raffinose and sucrose are not fermented. Glucose, trehalose, ethanol, ribitol, D-mannitol, D-glucitol, lactic acid and succinic acid are assimilated. No growth occurs on galactose, L-sorbose, sucrose, maltose, cellobiose, lactose, melibiose, raffinose, melezitose, inulin, soluble starch, D-xylose, L-arabinose, D-arabinose, D-ribose, L-rhamnose, D-glucosamine, methanol, glycerol, erythritol, methyl $\alpha$-D-glucoside, salicin, citrate or inositol. Positive for ethylamine hydrochloride and cadaverine, but negative for nitrate. Growth is observed at $30{ }^{\circ} \mathrm{C}$, but not at $37{ }^{\circ} \mathrm{C}$. No growth is observed on YM agar with $10 \% \mathrm{NaCl}$ or on $50 \%$ glucose $/ 0.5 \%$ yeast extract. No growth is observed in the presence of $50 \%(\mathrm{w} /$ v) glucose. Starch-like compounds are not produced. No growth with $100 \mu \mathrm{g}$ cycloheximide $\mathrm{ml}^{-1}$.

The type strain is CLQCA-10-114 ${ }^{\mathrm{T}} \quad\left(=\mathrm{CBS} \quad 12184^{\mathrm{T}}=\right.$ NCYC $3744^{\mathrm{T}}$ ), isolated from the fruit of an unidentified species of bramble (Rubus sp.), Maquipucuna, Ecuador.

\section{Acknowledgements}

S.A.J. would like to thank Mary Parker of the Imaging and Microscopy Group (IMG) at the IFR for her kind and invaluable assistance with scanning electron microscopic imaging. S. A. J., C. J. B, K. C. and I. N. R. were supported at the IFR by a BBSRC Competitive Strategic Grant. G. M. C. was supported by an EU Erasmus award. E. J.C.B. and P.P.B. were supported by the Pontificia Universidad Católica del Ecuador.

\section{References}

Boonmak, C., Jindamorakot, S., Kawasaki, H., Yongmanitchai, W., Suwanarit, P., Nakase, T. \& Limtong, S. (2009). Candida siamensis sp. nov., an anamorphic yeast species in the Saturnispora clade isolated in Thailand. FEM Yeast Res 9, 668-672.

Canelhas, M. R., Barbosa, A. C., Medeiros, A. O., Lee, C.-F., Huang, L.-Y., Lachance, M. A. \& Rosa, C. A. (2011). Saturnispora serradocipensis sp. nov. and Saturnispora gosingensis sp. nov., two ascomycetous yeasts from ephemeral habitats. Antonie van Leeuwenhoek 99, 241-247.

Felsenstein, J. (1985). Confidence limits on phylogenies: an approach using the bootstrap. Evolution 39, 783-791.

James, S. A., Collins, M. D. \& Roberts, I. N. (1996). Use of an rRNA internal transcribed spacer region to distinguish phylogenetically closely related species of the genera Zygosaccharomyces and Torulaspora. Int J Syst Bacteriol 46, 189-194.

Kurtzman, C. P. (1998). Saturnispora Liu \& Kurtzman. In The Yeasts, a Taxonomic Study, 4th edn, pp. 387-390. Edited by C. P. Kurtzman \& J. W. Fell. Amsterdam: Elsevier.

Kurtzman, C. P. (2006). New species and new combinations in the yeast genera Kregervanrija gen. nov., Saturnispora and Candida. FEM Yeast Res 6, 288-297.

Kurtzman, C. P., Robnett, C. J. \& Basehoar-Powers, E. (2008). Phylogenetic relationships among species of Pichia, Issatchenkia and Williopsis determined from multigene sequence analysis, and the proposal of Barnettozyma gen. nov., Lindnera gen. nov. and Wickerhamomyces gen. nov. FEMS Yeast Res 8, 939-954.

Limtong, S., Kaewwichian, R., Am-In, S., Boonmak, C., Jindamorakot, S., Yongmanitchai, W., Srisuk, N., Kawasaki, H. \& Nakase, T. (2010). Three anamorphic yeast species Candida sanitii sp. 
nov., Candida sekii sp. nov. and Candida suwanaritii, three novel yeasts in the Saturnispora clade isolated in Thailand. FEMS Yeast Res 10, 114-122.

Liu, Z. W. \& Kurtzman, C. P. (1991). Phylogenetic relationships among species of Williopsis and Saturnospora gen. nov. as determined from partial rRNA sequences. Antonie van Leeuwenhoek 60, 21-30.

Morais, P. B., Lachance, M. A. \& Rosa, C. A. (2005). Saturnispora hagleri sp. nov., a yeast species isolated from Drosophila flies in Atlantic rainforest in Brazil. Int J Syst Evol Microbiol 55, 1725-1727.

O'Donnell, K. (1993). Fusarium and its near relatives. In The Fungal Holomorph: Mitotic, Meiotic and Pleomorphic Speciation in Fungal Systematics, pp. 225-233. Edited by D. R. Reynolds \& J. W. Taylor. Wallingford, UK: CAB International.
Pearson, W. R. \& Lipman, D. J. (1988). Improved tools for biological sequence comparison. Proc Natl Acad Sci U S A 85, 2444-2448.

Saitou, N. \& Nei, M. (1987). The neighbor-joining method: a new method for reconstructing phylogenetic trees. Mol Biol Evol 4, 406-425.

Thompson, J. D., Higgins, D. G. \& Gibson, T. J. (1994). CLUSTAL W: improving the sensitivity of progressive multiple sequence alignment through sequence weighting, position-specific gap penalties and weight matrix choice. Nucleic Acids Res 22, 4673-4680.

White, T. J., Bruns, T., Lee, S. \& Taylor, J. W. (1990). Amplification and direct sequencing of fungal ribosomal RNA genes for phylogenetics. In PCR Protocols: A Guide to Methods and Applications, pp. 315-322. Edited by M. A. Innis, D. H. Gelfand, J. J. Sninsky \& T. J. White. New York: Academic Press. 